BMJ Nutrition,

Prevention \& Health

\section{Relationship between maternal body composition during pregnancy and infant's birth weight in Nairobi informal settlements, Kenya}

To cite: Wanjohi MN, Ogada I, Wekesah FM, et al. Relationship between maternal body composition during pregnancy and infant's birth weight in Nairobi informal settlements, Kenya. BMJ Nutrition, Prevention \& Health 2020;3:e000060. doi:10.1136/ bmjnph-2019-000060

For numbered affiliations see end of article.

\section{Correspondence to} Ms Milkah Njeri Wanjohi, Health and Systems for Health Unit, African Population and Health Research Center, APHRC Campus, Kitisuru, Nairobi PO Box 10787-00100, Kenya; mwanjohi@aphrc.org and

Mr Christopher KhayekaWandabwa, School of Pharmaceutical Science and Technology (SPST), Health Science Platform, Tianjin University, Tianjin 300072, China;

khayekachris@yahoo.com

Received 5 November 2019 Revised 20 May 2020 Accepted 28 May 2020 Published Online First 23 July 2020
Check for updates

(C) Author(s) (or their employer(s)) 2020. Re-use permitted under CC BY-NC. No commercial re-use. See rights and permissions. Published by BMJ.

\section{ABSTRACT}

Background Maternal nutrition depletion during pregnancy compromises fetal programming, and is a cause of adverse birth outcomes. Maternal body composition measurement using direct body composition assessment methods such as the deuterium dilution technique provides better prediction of birth outcomes as compared with commonly used techniques like anthropometry. This study assessed body composition of pregnant mothers in urban informal settlements in Nairobi, Kenya, and established the relationship between maternal body composition and infant birth weight.

Methods Deuterium dilution technique was used to determine body composition, including total body water (TBW), fat-free mass (FFM) and fat mass (FM), among 129 pregnant women who were enrolled into the study in their first or second trimester. Descriptive statistics and regression analysis were applied using Stata V.13.

Results The mean TBW, FFM and FM were $33.3 \mathrm{~L}( \pm 4.7)$, $45.7 \mathrm{~kg}( \pm 6.5)$ and $17.01 \mathrm{~kg}( \pm 7.4)$, respectively. Both TBW and FFM were significantly related to maternal age and gestation/pregnancy stage during body composition assessment while FM was significantly associated with gestation stage during body composition assessment. TBW and FFM were significantly lower in younger mothers ( $<20$ years) compared with older mothers ( $\geq 20$ years). The mean birth weight was $3.3 \mathrm{~kg} \pm 0.42 \mathrm{~kg}$. There was a positive association between infant birth weight and maternal TBW $(p=0.031)$ and FFM ( $p=0.027)$, but not FM $(p=0.88)$.

Conclusion Non-fat components of the body (TBW and FFM) have a positive association with birth weight. Therefore, interventions to improve optimal maternal feeding practices, to enhance optimal gains in FFM and TBW during pregnancy are recommended, especially among young mothers.

\section{INTRODUCTION}

Birth weight is an important predictor of child health, nutrition status and survival. ${ }^{1}$ Low birth weight (LBW) is associated with increased risk of neonatal death and child undernutrition ${ }^{2}$ which has adverse health and developmental consequences from childhood through to adulthood. ${ }^{3-5}$ Similarly, high birth weight is a
What this paper add

- Maternal TBW and FFM have a positive relationship with infant's birth weight while FM does not.

- TBW, FFM and FM were significantly lower among younger mothers $(<20$ years), compared to older mothers ( $>20$ years), suggesting targeted interventions on improving maternal nutrition in these and similar settings especially among young mothers for improved child health and well-being.

TBW, FFM and FM increase as pregnancy progresses.

major risk factor for childhood obesity, and consequent adulthood obesity, and other chronic diseases. ${ }^{67}$ Maternal body composition during pregnancy is an indicator of maternal nutrition and an important predictor of birth outcomes, including birth weight. ${ }^{8}$ Maternal body composition and nutrient stores during pregnancy influence the availability of nutrients for fetal growth and development, ${ }^{8}$ with significant effects on fetal genetic development, ${ }^{9}$ immune function ${ }^{10}$ cardiovascular function, and birth weight. ${ }^{11-13}$

The two-compartment model of body composition assessment subdivides the human total body weight into fat mass (FM) and fatfree mass (FFM). FM refers to the total amount of fat in the body, while FFM refers to the part that is non-fat, including proteins, bone mass, non-bone mass and total body water (TBW). ${ }^{14}$ TBW refers to the total water content of the body, including intracellular and extracellular body water. In normal adults, TBW is approximately $73 \%$ of the FFM. ${ }^{1415}$

Direct body composition assessment methods such as the deuterium dilution technique are more objective in body composition assessment than traditional methods like anthropometric and skinfold measurements. ${ }^{8} 1617$ The deuterium dilution technique is a gold standard method of direct 
Table 1 Participant's sociodemographic and economic characteristics

\begin{tabular}{|c|c|c|c|}
\hline \multicolumn{2}{|c|}{ Characteristics } & \multirow{2}{*}{$\begin{array}{l}\begin{array}{l}n=125 \\
n(\%)\end{array} \\
73(58.4)\end{array}$} & \multirow[t]{2}{*}{ Mean+SD } \\
\hline Informal & Korogocho & & \\
\hline settlement & Viwandani & $52(41.6)$ & \\
\hline \multirow{5}{*}{$\begin{array}{l}\text { Maternal age } \\
\text { in complete } \\
\text { years }\end{array}$} & $<20$ & $26(20.8)$ & \multirow[t]{5}{*}{$23.8+5.2$} \\
\hline & $20-24$ & 42 (33.6) & \\
\hline & $25-29$ & $36(28.8)$ & \\
\hline & $\geq 30$ & $13(10.4)$ & \\
\hline & $\begin{array}{l}\text { Don't know/can't } \\
\text { remember }\end{array}$ & $8(6.4)$ & \\
\hline
\end{tabular}

\begin{tabular}{|c|c|c|}
\hline \multirow[t]{4}{*}{ Parity } & 0 & $47(37.6)$ \\
\hline & $1-2$ & $60(48)$ \\
\hline & $3-4$ & $13(10.4)$ \\
\hline & $5-7$ & $5(4)$ \\
\hline \multirow[t]{3}{*}{ Marital status } & Single & $26(20.8)$ \\
\hline & Married/in union & $95(76)$ \\
\hline & Others & $4(3.2)$ \\
\hline \multirow[t]{8}{*}{ Ethnic group } & Somali/Borana/Garre & $7(5.6)$ \\
\hline & Kikuyu and Embu & $38(30.4)$ \\
\hline & Kamba & $18(14.4)$ \\
\hline & Kisii & $4(3.2)$ \\
\hline & Luhya & $26(20.8)$ \\
\hline & Luo & $23(18.4)$ \\
\hline & Taita & $2(1.6)$ \\
\hline & Others & $7(5.6)$ \\
\hline \multirow[t]{4}{*}{ Religion } & Christian & $111(88.8)$ \\
\hline & Muslim & $9(7.2)$ \\
\hline & Traditional & $1(0.8)$ \\
\hline & Others & $4(3.2)$ \\
\hline \multirow{5}{*}{$\begin{array}{l}\text { Highest level } \\
\text { of education }\end{array}$} & None/less than primary & $21(16.8)$ \\
\hline & Primary school & $80(64.0)$ \\
\hline & Secondary school & $16(12.8)$ \\
\hline & College/university & $2(1.6)$ \\
\hline & Missing & $6(4.8)$ \\
\hline \multirow[t]{4}{*}{ Occupation } & Unemployed & $88(70.4)$ \\
\hline & Employed (informal) & $27(21.6)$ \\
\hline & Employed (formal) & $6(4.8)$ \\
\hline & Missing & $4(3.2)$ \\
\hline \multirow{2}{*}{$\begin{array}{l}\text { Pregnancy } \\
\text { stage } \\
\text { at body } \\
\text { composition } \\
\text { assessment }\end{array}$} & First trimester & $20(16.0)$ \\
\hline & Second trimester & $105(84.0)$ \\
\hline \multirow[t]{3}{*}{$\begin{array}{l}\text { Number of } \\
\text { ANC visits (at } \\
\text { the time of } \\
\text { BC) }\end{array}$} & & \\
\hline & 0 & $20(16.0)$ \\
\hline & $1-3$ & $50(40.0)$ \\
\hline
\end{tabular}

Continued

\begin{tabular}{lll}
\hline Table 1 Continued & \\
\hline $\begin{array}{l}\mathbf{n}=125 \\
\mathbf{n}(\%)\end{array}$ & Mean+SD \\
\hline \multicolumn{1}{l}{$\begin{array}{l}\text { Characteristics } \\
\text { Number of }\end{array}$} & \\
$\begin{array}{l}\text { illnesses } \\
\text { experienced } \\
\text { during } \\
\text { pregnancy }\end{array}$ & 0 & \\
\hline & 1 & $38(30.4)$ \\
\hline & 2 & $39(31.2)$ \\
\hline & $3-5$ & $31(24.8)$ \\
\hline
\end{tabular}

ANC, antenatal care; BC, body composition.

body composition assessment and is based on the assumption that the water content of FFM is relatively constant at approximately $73 \%$ in normal adults with an average increase of about $2 \%$ during pregnancy period. ${ }^{1416}$

Urban informal settings, where about $70 \%$ of urban dwellers in low and middle-income countries live, are characterised by poor maternal and child health indicators, mainly due to high levels of poverty and poor access to health services. ${ }^{18}{ }^{19}$ In these settings, LBW contributes significantly to premature child deaths and child stunting for children less than 5 years. ${ }^{20}{ }^{21}$ However, there is paucity of evidence on maternal body composition during pregnancy and its relationship with birth weight in the same settings which would form a pertinent part of the overall evidence base towards policy framework and guidelines for more rational maternal child health public health planning, with a focus on the unprivileged population segments. This study aimed to establish the body composition of pregnant women using the stable isotope (deuterium) dilution technique and investigated the relationship between maternal body composition and birth weight among pregnant women in two urban informal settlements in Nairobi, Kenya.

\section{METHODS \\ Study setting and participants}

The study was conducted in the Korogocho and Viwandani slums in Nairobi, settings characterised by poor access to basic amenities including portable water, waste disposal, health and education services. ${ }^{21-23}$ These settings also have poor housing, high levels of food insecurity and are exposed to high levels of unemployment, violence and teenage pregnancy. ${ }^{24}$ In addition, Kenyan urban informal settlements have higher infant mortality rates (75 in 1000 live births) compared with other subpopulations, ${ }^{26}$ and birth weight is a major cause of poor child health and deaths in the two settlements. ${ }^{2021}$

A calculated sample of 129 women in their first and second trimesters were recruited to participate in this study, which was nested within a broader maternal infant and young child nutrition (MIYCN) study. The 


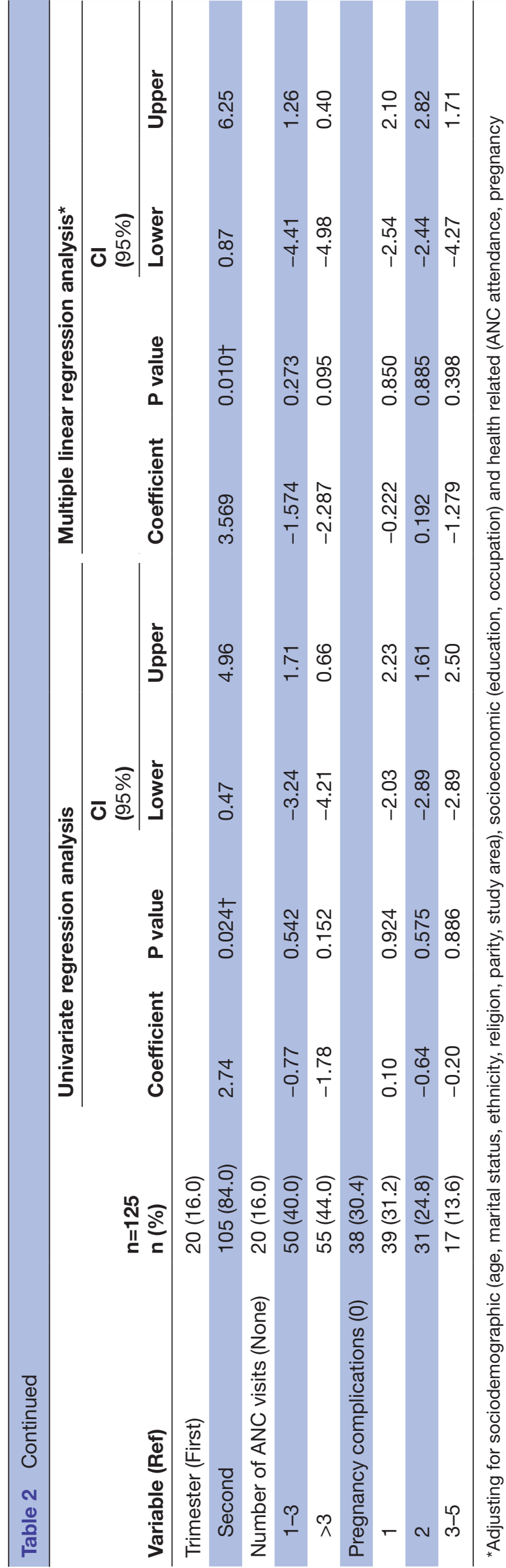

MIYCN study involved the follow-up of a cohort of over 1000 women from pregnancy until 1 year after delivery to determine the feeding practices and nutrition status of mothers and children in this cohort in the two slums. ${ }^{27}$ The MIYCN study was implemented from 2012 to 2014 within the Nairobi Urban Health and Demographic Surveillance System (NUHDSS), which is run by the African Population and Health Research Center. NUHDSS has been in operation since 2002 and involves surveillance of the population living in Korogocho and Viwandani, to monitor their health and demographic outcomes. ${ }^{22}$ Systematic sampling was used to select the 129 pregnant women from the larger cohort of 1000 women recruited into the MIYCN study, whereby every eighth eligible mothers listed in the MIYCN study were recruited to participate in this study.

\section{Study procedure}

The pregnant women who were sampled to participate in the study were contacted by the researcher, informed about the study and invited to a central place within the study community, where the deuterium dosing, saliva sample collection, anthropometric measurements (weight and height) and a face-to-face interview on socioeconomic, demographic, health and health-seeking behaviour and pregnancy characteristics were conducted. Their gestation stage at the time of body composition was established through the date of their last menstrual period as recorded in the mother and child booklet (issued during antenatal care (ANC) visits), and recall for those who did not have the mother and child booklet. The deuterium dilution procedures were carried out by a professional specialist trained on this technique by the International Atomic Energy Agency (IAEA), while the interviews were conducted by trained research assistants.

Deuterium dosage and analysis for body composition of the pregnant mothers was done as described by the IAEA. ${ }^{14}$ The mothers were then followed up after delivery to collect their infant's birth weight and sex, as recorded in the mother and child health booklet at delivery in the hospital.

\section{Data analysis}

Stata V.13 (StataCorp, College Station, TX) was used for statistical analysis. Descriptive summary statistics were calculated for socioeconomic and demographic characteristics, and body composition measurements. The relationship between maternal characteristics (sociodemographic, economic, health), maternal body composition (TBW, FFM, FM) and infant's birth weight was determined using linear regression analysis while controlling for potential confounders.

\section{RESULTS}

Four out of the 129 mothers recruited to participate in the study did not complete the deuterium dosage procedure and were therefore excluded in the analysis of maternal characteristics. Thus, a total sample of 125 mothers were 


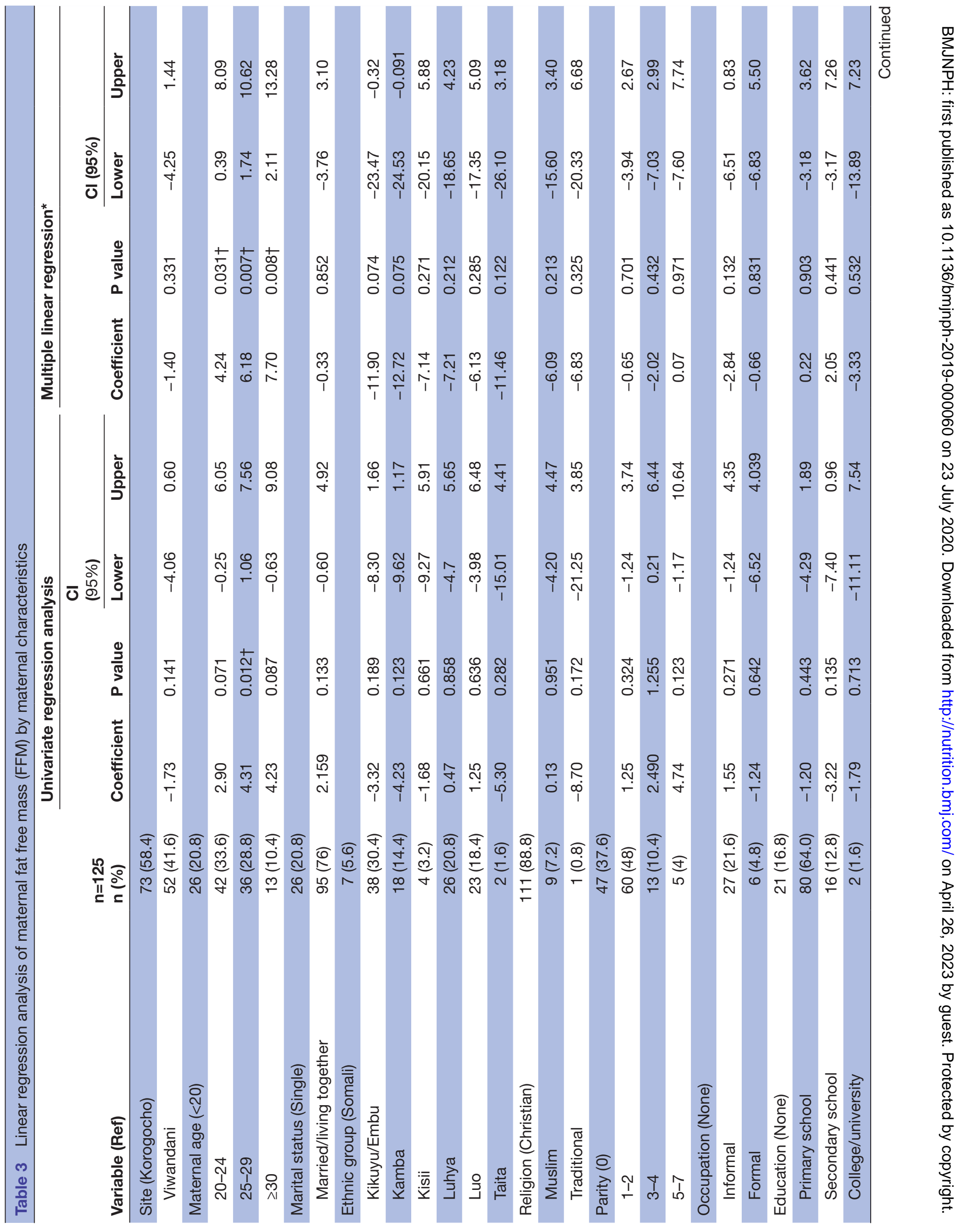




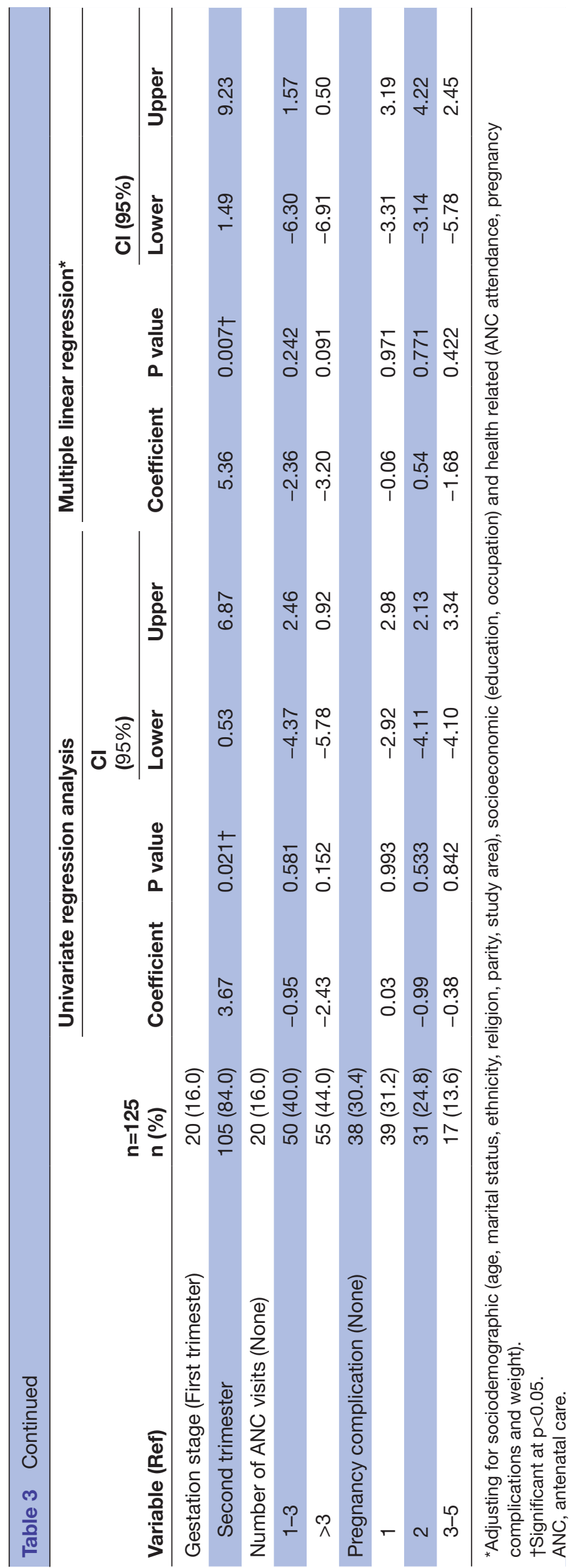

included in the analysis. In addition, details of infants born to 27 of the mothers could not be established for reasons that some mothers had moved out of the study area (18), lost their babies through miscarriage or stillbirth (5), their babies were not weighed at birth (2) and refusal to continue participating in the study (2).

\section{Maternal characteristics}

Participants' socioeconomic and demographic characteristics are as described in table 1. Overall, the mean age of the participants was $23.8( \pm 5.2)$ years, $21 \%$ were less than 20 years and a majority $(62 \%)$ were aged between 20 and 29 years. Majority of the participants $(84 \%)$ were in the second trimester of their pregnancy. Sixteen per cent had not attended any ANC. Slightly more than twothirds $(70 \%)$ of the women reported to have experienced at least one complication or illness during pregnancy.

\section{Maternal body composition \\ Total body water}

The participants' TBW ranged from 23.30 to $44.80 \mathrm{~L}$, the mean TBW was $33.3 \mathrm{~L}( \pm 4.7)$, which was $53.1 \%$ of the mean body weight. TBW had a significant association with maternal age and the gestational stage (trimester when the body composition assessment was done). TBW was significantly lower among younger mothers who were aged less than 20 years compared with older mothers (above 20 years). In addition, participants in the second trimester had a significantly higher TBW compared with those in the first trimester. There was no significant association between TBW and marital status, religion, parity, occupation, education, ANC visits and pregnancy illness/ complications during pregnancy, at both univariate and multiple regression analyses (table 2).

\section{Fat-free mass}

FFM ranged from 31.90 to $61.39 \mathrm{~kg}$, with a mean of $45.7 \mathrm{~kg}$ $( \pm 6.5)$. Age and gestation stage were found to have a significant relationship with FFM. Mothers younger than 20 years had significantly lower FFM compared with those aged 20 and above. In addition, FFM was significantly higher among mothers in the second trimester compared with those in the first trimester. There was no significant association between FFM and marital status, religion, parity, occupation, education, ANC visits and pregnancy illness/complications during pregnancy, at both univariate and multiple regression analyses (table 3).

\section{FM and body fat percentage}

The mean FM and body fat percentage in this study were $17.01 \mathrm{~kg}( \pm 7.4)$ and $26.8 \%( \pm 8.1)$, respectively. There was a significant relationship between FM and maternal age based on linear regression analysis. FM was significantly lower for mothers younger than 20 years compared with older mothers. There was no significant relationship between FM and residence, marital status, occupation, education, ANC visits and pregnancy complication, and gestation stage at body composition (table 4 ). 
Table 4 Linear regression analysis of maternal fat mass (FM) by maternal characteristics

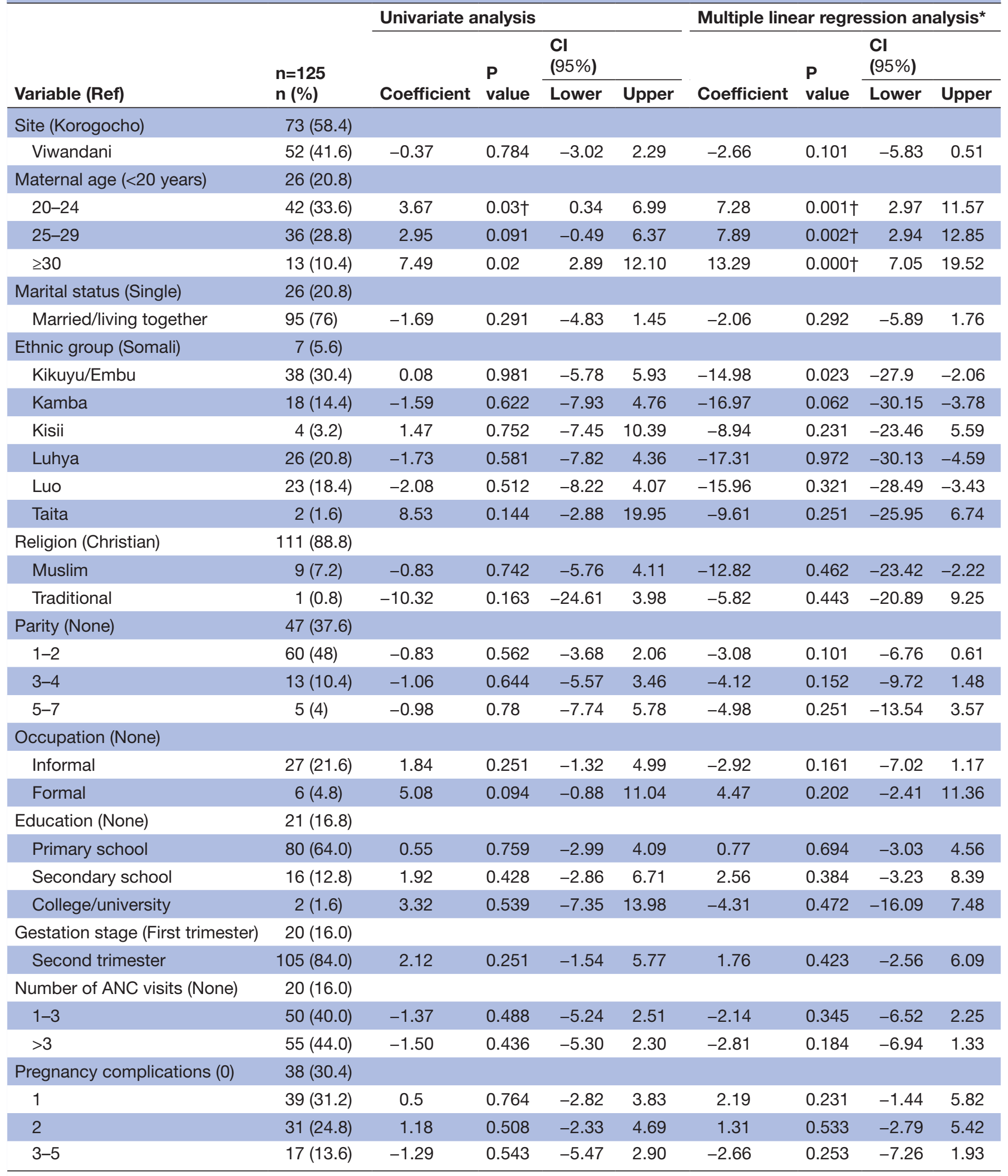

*Adjusting for sociodemographic (age, marital status, ethnicity, religion, parity, study area), socioeconomic (education, occupation) and health related (ANC attendance, pregnancy complications and weight).

$\dagger$ Significant at $p<0.05$.

ANC, antenatal care. 


\section{Infant's birth weight}

Infant's birth weight ranged from 2.2 to $4.2 \mathrm{~kg}$, with a mean birth weight of $3.3 \mathrm{~kg}( \pm 0.42)$. Birth weight was further categorised into LBW $(<2.5 \mathrm{~kg})$, normal birth weight $(2.5-4.0 \mathrm{~kg})$ and high birth weight $(>4.0 \mathrm{~kg}){ }^{28}$ Majority of the children (94\%) had normal birth weight, $3 \%$ of the children had LBW and the rest $(3 \%)$ had high birth weight. Linear regression analysis showed no significant association between birth weight and child's sex, maternal sociodemographic characteristics (age, marital status, ethnicity, religion, parity, study area), maternal socioeconomic characteristics (education) and pregnancy characteristics (ANC attendance, pregnancy complications) (table 5).

\section{Relationship between maternal body composition and birth weight}

Linear regression was applied to establish the relationship between maternal body composition (TBW, FFM, FM) and infant's birth weight. There was a significant relationship between birth weight and maternal TBW $(\mathrm{p}=0.031)$ and maternal FFM ( $p=0.027)$, but no significant relationship was found between birth weight and FM (0.88) at both univariate and multivariate analyses, respectively (table 6). In this multivariate analysis, variables that had a $p$ value $\leq 0.2$ in the regression of birth weight against maternal and child characteristics (table 5) were treated as potential confounders and hence included in the model; they include maternal age, ethnicity, gestation stage at body composition and ANC attendance.

\section{DISCUSSION}

The IAEA estimates that water makes up to approximately $70 \%-75 \%$ of an individual's body weight at birth, but decreases to about $40 \%-60 \%$ in adulthood. ${ }^{14}$ TBW in this study accounted for $53 \%$ of the total weight, which was within the IAEA estimated ranges. In addition, the IAEA estimates that optimal TBW among women (nonpregnant) ranges from 26 to $33 \mathrm{~L}$, the mean TBW in this study was 33.3, slightly higher than the IAEA estimates among non-pregnant women; this could be due to the pregnancy, since studies have shown an increase in TBW levels in the course of pregnancy. ${ }^{28}$ Related findings have reported the mean TBW of pregnant women in the first and second trimesters to be between 38.68 and $40.61 \mathrm{~L}$, respectively, ${ }^{29}{ }^{30}$ the slight variation could be as a result of the varying study contexts.

The Kenya National Guidelines for Healthy Diets and Physical Activity 2017 highlight that optimal body fat percentage for women ranges from $12 \%$ to $25 \%$. The mean body fat percentage for women in this study was $26.8 \%$, slightly higher than the optimal ranges as stated in the guidelines, which would be as a result of the pregnancy, because maternal fat accretion during pregnancy occurs as a natural process to cater for fetal growth and development. ${ }^{31}$ The reported lower body composition (TBW, FFM and FM) among teenage mothers compared
Table 5 Linear regression analysis of infant's birth weight by maternal and child characteristics

\begin{tabular}{lllll}
\hline & & & \multicolumn{2}{l}{ Cl (95\%) } \\
\cline { 4 - 5 } Variable (Ref) & Coefficient & P value & Lower & Upper \\
\hline $\begin{array}{l}\text { Site (Korogocho) } \\
\text { Viwandani }\end{array}$ & -0.04 & 0.650 & -0.21 & 0.13 \\
$\begin{array}{c}\text { Child characteristics } \\
\begin{array}{l}\text { Child's sex } \\
\text { (Female) }\end{array}\end{array}$ & & & & \\
$\quad$ Male & 0.14 & 0.872 & -1.56 & 0.18 \\
\hline
\end{tabular}

Maternal

characteristics

\begin{tabular}{|c|c|c|c|c|}
\hline \multicolumn{5}{|l|}{$\begin{array}{l}\text { Maternal age } \\
\text { (<20years) }\end{array}$} \\
\hline $20-24$ & 0.14 & 0.054 & 0.00 & 0.27 \\
\hline $25-29$ & 0.11 & 0.132 & -0.03 & 0.24 \\
\hline$\geq 30$ & 0.11 & 0.221 & -0.06 & 0.27 \\
\hline \multicolumn{5}{|l|}{ Marital status (Single) } \\
\hline $\begin{array}{l}\text { Married/living } \\
\text { together }\end{array}$ & 0.09 & 0.385 & -0.11 & 0.28 \\
\hline \multicolumn{5}{|l|}{ Ethnic group (Somali) } \\
\hline Kikuyu/Embu & 0.20 & 0.326 & -0.19 & 0.58 \\
\hline Kamba & 0.20 & 0.370 & -0.24 & 0.63 \\
\hline Kisii & 0.49 & 0.115 & -0.10 & 1.08 \\
\hline Luhya & 0.16 & 0.457 & -0.25 & 0.56 \\
\hline Luo & 0.31 & 0.141 & -0.10 & 0.71 \\
\hline Taita & -0.58 & 0.201 & -1.47 & 0.31 \\
\hline \multicolumn{5}{|l|}{ Religion (Christian) } \\
\hline Muslim & -0.14 & 0.371 & -0.46 & 0.18 \\
\hline \multicolumn{5}{|l|}{ Parity (0) } \\
\hline $1-2$ & 0.09 & 0.342 & -0.09 & 0.27 \\
\hline $3-4$ & 0.05 & 0.756 & -0.25 & 0.34 \\
\hline $5+$ & 0.30 & 0.173 & -0.13 & 0.73 \\
\hline \multicolumn{5}{|l|}{ Occupation (None) } \\
\hline Informal & 0.00 & 0.982 & -0.20 & 0.21 \\
\hline Formal & 0.03 & 0.878 & -0.35 & 0.41 \\
\hline \multicolumn{5}{|l|}{ Education (None) } \\
\hline Primary school & 0.04 & 0.740 & -0.18 & 0.26 \\
\hline Secondary school & 0.03 & 0.862 & -0.29 & 0.34 \\
\hline College/university & -0.02 & 0.947 & -0.63 & 0.59 \\
\hline \multicolumn{5}{|l|}{$\begin{array}{l}\text { Number of ANC visits } \\
\text { (None) }\end{array}$} \\
\hline $1-3$ & 0.17 & 0.291 & -0.15 & 0.49 \\
\hline$>3$ & 0.08 & 0.623 & -0.23 & 0.39 \\
\hline \multicolumn{5}{|c|}{ Pregnancy complications } \\
\hline 1 & -0.10 & 0.371 & -0.32 & 0.12 \\
\hline 2 & -0.06 & 0.636 & -0.28 & 0.17 \\
\hline $3-5$ & 0.09 & 0.487 & -0.17 & 0.35 \\
\hline
\end{tabular}

ANC, antenatal care. 
Table 6 Linear regression of birth weight by maternal body composition (TBW, FFM and FM)

\begin{tabular}{|c|c|c|c|c|c|c|c|c|}
\hline \multirow[b]{3}{*}{ Birth weight } & \multicolumn{4}{|c|}{ Univariate analysis } & \multicolumn{4}{|c|}{ Multiple linear regression analysis* } \\
\hline & \multirow[b]{2}{*}{ Coefficient } & \multirow[b]{2}{*}{$P$ value } & \multicolumn{2}{|c|}{ CI (95\%) } & \multirow[b]{2}{*}{ Coefficient } & \multirow[b]{2}{*}{$P$ value } & \multicolumn{2}{|c|}{ CI (95\%) } \\
\hline & & & Lower & Upper & & & Lower & Uppe \\
\hline TBW & 0.02 & $0.005 \dagger$ & 0.01 & 0.04 & 0.022217 & $0.031 \dagger$ & 0.002 & 0.04 \\
\hline FFM & 0.02 & $0.003 \dagger$ & 0.01 & 0.03 & 0.016453 & $0.027 \dagger$ & 0.001 & 0.03 \\
\hline FM & 0.01 & 0.276 & 0.00 & 0.02 & 0.000978 & 0.884 & -0.01 & 0.01 \\
\hline
\end{tabular}

${ }^{*}$ Adjusting for maternal age, ethnicity, trimester when body composition was done and antenatal care (ANC) visits.

†Significant at $\mathrm{p}<0.05$.

FFM, fat-free mass; FM, fat mass; TBW, total body water.

with older mothers concurs with similar studies in other countries, for instance, younger mothers in Mexico had slightly lower TBW, FFM and FM compared with older mothers in both second and third trimesters of their pregnancy. ${ }^{32}$ It is documented that teenage pregnancy depletes both fat and lean body mass among teenage mothers ${ }^{33}$ and also hinders their linear growth. Furthermore, the WHO reports that pregnant teenagers have not achieved full growth and development and continue to grow even during the pregnancy. ${ }^{34}$ This could explain the lower body composition levels (TBW, FFM, FM) among the young mothers compared with their older and mature counterparts. It is worth noting that lower FM levels are associated with maternal malnutrition in Kenya. ${ }^{35}$

The findings of this study reveal that maternal TBW and FFM increase as pregnancy progresses, from first to second trimester which is comparative to insights from a study in Sweden ${ }^{6}$ which established that women in the third trimester (32 weeks) have a higher TBW level compared with those in the second trimester (14 weeks' gestation) with similar trends in Mexico, where TBW and FFM increased as women progressed from second to third trimester. ${ }^{16}$ Butte et al hypothesised that the increase in TBW in the course of pregnancy is among the reasons for weight gain during pregnancy ${ }^{29}$ while Ghezzi et al indicate that total intracellular and extracellular water significantly increase as pregnancy advances and return to the pre-pregnancy values within 60 days after delivery. ${ }^{36}$ Among the components that contribute to increased TBW during pregnancy are the increased blood volume and extracellular fluids to support fetal development, while the progressive growth of uterine tissue, mammary and soft tissues contributes to the increased FFM as pregnancy progresses. ${ }^{37}$

The positive association between TBW and birth weight herein reported is amenable to observations in the USA and Tanzania ${ }^{38}{ }^{39}$ corresponding to a developed and developing nation, respectively, that established a positive correlation between TBW and birth weight, respectively, using the deuterium dilution methodology. It is important to note that lower TBW has been associated with intrauterine growth retardation, one of the risk factors for LBW. $^{40}$ The positive relationship between FFM and birth weight further compares with studies among Jamaican women in their first trimester and among Caucasian pregnant women in their second and third trimesters. ${ }^{40}$ In these two studies, FFM was found to have a positive relationship with birth weight and to be a strong predictor of birth weight, whereby higher maternal FFM was linked with higher birth weights. An FFM higher than $40.76 \mathrm{~kg}$ has been associated with about a threefold risk for high birthweight babies $\left(>4 \mathrm{~kg}\right.$ ) among Chinese women ${ }^{42}$ and hence increased risks of obesity in childhood and adulthood, and associated chronic diseases. ${ }^{7}$

Although there was no association between FM and birth weight in this study, a Swedish study found positive correlation between birth weight and FM of women in the third trimester using anthropometric assessments. ${ }^{12}$ The current study, however, focused on women in the first and second trimesters. In addition, stores of certain types of fats such as the polyunsaturated fatty acids have been shown to promote optimal fetal and infant development and breast milk production post partum. ${ }^{12} 43$

This study focused on women in the first and second trimesters, and hence there may be body composition changes in the third trimester that were not captured in the study, which we acknowledge as a limitation. In addition, ANC attendance and complications experienced during pregnancy were based on the mothers' self-report and hence potential for recall bias. Use of the deuterium dilution technique assessment, a gold standard method of body composition assessment, is a key strength of the study, as this technique is considered as a more objective method of nutrition assessment compared with other methods such as anthropometry ${ }^{8}$ which have been previously used to establish maternal nutrition status in the study area.

\section{CONCLUSION}

Maternal body composition TBW, FFM and FM among pregnant women in the study setting increase as pregnancy progresses among the pregnant women examined, but each of the components (TBW, FFM and FM) was significantly lower among teenage mothers $(<20$ years $)$ compared with older mothers. Low maternal fat mas in Kenya has been associated with poor maternal nutrition, which has been shown to increase the risks of adverse birth outcomes including LBW, preterm births and child deaths. The positive association between TBW and FFM 
and birth weight may be an indication of the important role played by TBW which includes the intracellular and extracellular body fluids and FFM which includes proteins and body tissue, in the fetal growth and development, and hence their influence on the infant's general birth weight. The low TBW, FFM and FM among teenage mothers compared with older mothers are therefore of concern, especially TBW and FFM measurements which had a positive association with infant's birth weight. Interventions focusing on improving maternal nutrition and gains in FFM and TBW during pregnancy in these and similar settings especially among young mothers would be a worthwhile quest for improved child health and well-being. This could be done through integrating nutrition counselling and support within the youth-friendly programmes that are specifically designed and targeted for youths and adolescents. This is even more important owing to the relatively high prevalence of teenage pregnancies among the urban poor and in the study area.

\section{Author affiliations}

${ }^{1}$ Maternal and Child Wellbeing, African Population and Health Research Center, Nairobi, Kenya

${ }^{2}$ Department of Human Nutrition, St Francis Xavier University, Antigonish, Nova Scotia, Canada

${ }^{3}$ Department of Food Nutrition and Dietetics, Kenyatta University, Nairobi, Kenya ${ }^{4}$ Health and Systems for Health Unit, African Population and Health Research Center, Nairobi, Kenya

${ }^{5}$ Julius Global Health, Julius Center for Health Sciences and Primary Care, University Medical Center, Utrecht University, Utrecht, Netherlands

${ }^{6}$ School of Pharmaceutical Science and Technology (SPST), Health Science Platform, Tianjin University, Tianjin, China

${ }^{7}$ Wellcome Trust, London, United Kingdom

\section{Twitter Frederick Murunga Wekesah @Wekesah}

Acknowledgements The authors highly acknowledge the data collection and management team and the study participants: Drs Catherine Kyobutungi and Alex Ezeh of APHRC, Nyovani J Madise, then of the University of Southampton and now of African Institute for Development Policy (AFIDEP), and Paula Griffiths of Loughborough University, Professor Shane Norris of the University of the Witwatersrand, Professor Rachel Musoke of University of Nairobi for their input in the study design, Dr Dorcas Mbithe and Dr Judith Munga of Kenyatta University for their contribution to the study and Dr Christine Mwangi and Ms Jedida Ndinda of Kenya Medical Research Institute for the laboratory analysis of the samples, $\mathrm{Dr}$ Victor Owino of International Atomic Energy Agency for his input in the manuscript writing.

Contributors MNW was involved in the design of the study, data collection, analysis and manuscript writing. 10 and EWKM were involved in the design of the study, guided the data collection and analysis, and manuscript writing. FMW was involved in the design of the study and review of the draft manuscript. CKW was involved in the data analysis and draft manuscript development of all versions of the manuscript. All authors read and approved the final version of the manuscript.

Funding This study was funded by the Wellcome Trust (Grant No 097146/Z/11/Z). This research was also made possible through the generous core funding for APHRC by the William and Flora Hewlett Foundation (Grant No 2009-40510), and the Swedish International Cooperation Agency (SIDA) (Grant No 2011-001578). PG is supported by a British Academy Mid-Career Fellowship (Ref: MD120048).

\section{Competing interests None declared.}

Patient consent for publication Not required.

Ethics approval The study was approved by the Kenya Medical Research Institute (KEMRI) Ethical Review Board and the National Commission for Science and Technology and Innovation. Voluntary informed consent was sought from each study participant prior to the interviews and sample collection.
Provenance and peer review Not commissioned; externally peer reviewed.

Data availability statement Data are available upon reasonable request. Deidentified participant data are available upon reasonable request from African Population and Health Research Center, PO Box 10787-00100, APHRC Campus, Kitisuru, Nairobi, Kenya. Email: info@aphrc.org. Telephone: +254 (20) 4001000 , 266 2244, or 266 2255. Mobile: +254 722205 933, 733410 102. Fax: +254 (20) 4001101.

Open access This is an open access article distributed in accordance with the Creative Commons Attribution Non Commercial (CC BY-NC 4.0) license, which permits others to distribute, remix, adapt, build upon this work non-commercially, and license their derivative works on different terms, provided the original work is properly cited, appropriate credit is given, any changes made indicated, and the use is non-commercial. See: http://creativecommons.org/licenses/by-nc/4.0/.

\section{ORCID iDs}

Milkah Njeri Wanjohi http://orcid.org/0000-0003-4289-4762

Irene Ogada http://orcid.org/0000-0001-5214-5509

Frederick Murunga Wekesah http://orcid.org/0000-0003-2333-3054

Christopher Khayeka-Wandabwa http://orcid.org/0000-0002-9891-6046

Elizabeth W Kimani-Murage http://orcid.org/0000-0001-5272-616X

\section{REFERENCES}

1 da Silva Lopes K, Ota E, Shakya P, et al. Effects of nutrition interventions during pregnancy on low birth weight: an overview of systematic reviews. BMJ Glob Health 2017;2:e000389.

2 Christian P, Lee SE, Donahue Angel M, et al. Risk of childhood undernutrition related to small-for-gestational age and preterm birth in low- and middle-income countries. Int J Epidemiol 2013;42:1340-55.

3 Barker DJP. The developmental origins of adult disease. J Am Coll Nutr 2004;23:588S-95.

4 Victora GA L, Fall C, Hallal PC, et al. Sachdev, H. S.Maternal,Child Undernutrition Study, Group: Maternal and child undernutrition: consequences for adult health and human capital. Lancet 2008;371:340-57.

5 He Z, Bishwajit G, Yaya S, et al. Prevalence of low birth weight and its association with maternal body weight status in selected countries in Africa: a cross-sectional study. BMJ Open 2018;8:e020410.

6 Barker DJP, Osmond C, Kajantie E, et al. Growth and chronic disease: findings in the Helsinki birth cohort. Ann Hum Biol 2009;36:445-58.

7 Weng SF, Redsell SA, Swift JA, et al. Systematic review and metaanalyses of risk factors for childhood overweight identifiable during infancy. Arch Dis Child 2012;97:1019-26.

8 McCarthy EA, Strauss BJG, Walker SP, et al. Determination of maternal body composition in pregnancy and its relevance to perinatal outcomes. Obstet Gynecol Surv 2004;59:731-42. quiz 745736

9 Wu G, Bazer FW, Cudd TA, et al. Maternal nutrition and fetal development. J Nutr 2004:134:2169-72.

10 Phillips DIW. External influences on the fetus and their long-term consequences. Lupus 2006;15:794-800.

11 Poston L. Influence of maternal nutritional status on vascular function in the offspring. Microcirculation 2011;18:256-62.

12 Forsum E, Löf M, Olausson $\mathrm{H}$, et al. Maternal body composition in relation to infant birth weight and subcutaneous adipose tissue. $\mathrm{Br} \mathrm{J}$ Nutr 2006;96:408-14.

13 Kent E, O'Dwyer V, Fattah C, et al. Correlation between birth weight and maternal body composition. Obstet Gynecol 2013;121:46-50.

14 International Atomic Energy Agency: Introduction to Body Composition Assessment Using the Deuterium Dilution Technique with Analysis of Saliva Samples by Fourier Transform Infrared Spectrometry. In: IAEA HUMAN HEALTH SERIES No 12. Austria, Viena 2010

15 Widen EM, Gallagher D. Body composition changes in pregnancy: measurement, predictors and outcomes. Eur J Clin Nutr 2014;68:643-52.

16 Lof M, Forsum E. Hydration of fat-free mass in healthy women with special reference to the effect of pregnancy. Am J Clin Nutr 2004;80:960-5.

17 Most J, Marlatt KL, Altazan AD, et al. Advances in assessing body composition during pregnancy. Eur J Clin Nutr 2018;72:645-56.

18 Matthews Z, Channon A, Neal S, et al. Examining the "urban advantage" in maternal health care in developing countries. PLoS Med 2010;7:e1000327. 
19 United Nations Human Settlement Programme. Slums of the World:The face of urban poverty in the new millennium? In. Nairobi 2003.

20 Kyobutungi C, Ziraba AK, Ezeh A, et al. The burden of disease profile of residents of Nairobi's slums: results from a demographic surveillance system. Popul Health Metr 2008;6:1.

21 Abuya BA, Ciera J, Kimani-Murage E. Effect of mother's education on child's nutritional status in the slums of Nairobi. BMC Pediatr 2012;12:80.

22 Emina J, Beguy D, Zulu EM, et al. Monitoring of health and demographic outcomes in poor urban settlements: evidence from the Nairobi urban health and demographic surveillance system. J Urban Health 2011;88:200-18.

23 Kimani-Murage EW, Ngindu AM. Quality of water the slum dwellers use: the case of a Kenyan slum. J Urban Health 2007;84:829-38.

24 Kimani-Murage EW, Schofield L, Wekesah F, et al. Vulnerability to food insecurity in urban slums: experiences from Nairobi, Kenya. $J$ Urban Health 2014;91:1098-113.

25 Beguy D, Ndugwa R, Kabiru CW. Entry into motherhood among adolescent girls in two informal settlements in Nairobi, Kenya. $J$ Biosoc Sci 2013;45:721-42.

26 Kimani-Murage EW, Fotso JC, Egondi T, et al. Trends in childhood mortality in Kenya: the urban advantage has seemingly been wiped out. Health Place 2014;29:95-103.

27 Kimani-Murage EW, Kyobutungi C, Ezeh AC, et al. Effectiveness of personalised, home-based nutritional counselling on infant feeding practices, morbidity and nutritional outcomes among infants in Nairobi slums: study protocol for a cluster randomised controlled trial. Trials 2013;14:445.

28 World Health Organization. International statistical classification of diseases and related health Problems10th revision (ICD-10) version for 2010. in. Geneva: World Health Organization, 2010.

29 Butte NF, Ellis KJ, Wong WW, et al. Composition of gestational weight gain impacts maternal fat retention and infant birth weight. Am J Obstet Gynecol 2003;189:1423-32.

30 Larciprete $\mathrm{G}$, Valensise $\mathrm{H}$, Vasapollo $\mathrm{B}$, et al. Body composition during normal pregnancy: reference ranges. Acta Diabetol 2003;40 Suppl 1:s225-32.

31 Kopp-Hoolihan LE, van Loan MD, Wong WW, et al. Fat mass deposition during pregnancy using a four-component model. J Appl Physiol 1999;87:196-202.
32 Contreras Campos ME, Rodríguez-Cervantes N, Reza-López S, et al. Body composition and newborn birthweight in pregnancies of adolescent and mature women. Matern Child Nutr 2015;11:164-72.

33 Rah JH, Christian P, Shamim AA, et al. Pregnancy and lactation hinder growth and nutritional status of adolescent girls in rural Bangladesh. J Nutr 2008;138:1505-11.

34 World Health Organisation. Adolecsent Pregancy: Issues in Adolescent Health and Development. In: WHO discussion Papers on Adolescence Edited by WHO. Geneva: World Health Organisation: Department of Reproductive Health and Research, 2004.

35 Ettyang GA, van Marken Lichtenbelt WD, Oloo A, et al. Serum retinol, iron status and body composition of lactating women in Nandi, Kenya. Ann Nutr Metab 2003;47:276-83.

36 Ghezzi F, Franchi M, Balestreri D, et al. Bioelectrical impedance analysis during pregnancy and neonatal birth weight. Eur J Obstet Gynecol Reprod Biol 2001;98:171-6.

37 Institute of Medicine (US) Committee on Nutritional Status During Pregnancy and Lactation. Nutrition during pregnancy: Part I weight gain. Washington (DC: National Academies Press (US), 1990.

38 Butte NF, Ellis KJ, Wong WW, et al. Composition of gestational weight gain impacts maternal fat retention and infant birth weight. Am J Obstet Gynecol 2003;189:1423-32.

39 Kupka R, Manji KP, Wroe E, et al. Comparison of isotope dilution with bioelectrical impedance analysis among HIV-infected and HIVuninfected pregnant women in Tanzania. Int $J$ Body Compos Res 2011;9:1.

40 Gernand AD, Christian P, Schulze KJ, et al. Maternal nutritional status in early pregnancy is associated with body water and plasma volume changes in a pregnancy cohort in rural Bangladesh. J Nutr 2012;142:1109-15

41 Farah N, Stuart B, Donnelly V, et al. The influence of maternal body composition on birth weight. Eur J Obstet Gynecol Reprod Biol 2011;157:14-17.

42 Wang Y, Mao J, Wang W, et al. Maternal fat free mass during pregnancy is associated with birth weight. Reprod Health 2017;14:47

43 Crawford MA, Hassam AG, Stevens PA. Essential fatty acid requirements in pregnancy and lactation with special reference to brain development. Prog Lipid Res 1981;20:31-40. 